\title{
A Small RNA Resembling the Beet Western Yellows Luteovirus ST9-Associated RNA Is a Component of the California Carrot Motley Dwarf Complex
}

\author{
Michael T. Watson, Tongyan Tian, Elizabeth Estabrook, and Bryce W. Falk
}

Department of Plant Pathology, University of California, Davis 95616.

Accepted for publication 3 November 1997.

\begin{abstract}
Watson, M. T., Tian, T., Estabrook, E., and Falk, B. W. 1998. A small RNA resembling the beet western yellows luteovirus ST9-associated RNA is a component of the California carrot motley dwarf complex. Phytopathology 88:164-170.

Virions were purified from Anthriscus cerefolium or Coriandrum sativum plants infected with the viruses that cause California carrot motley dwarf. Sodium dodecyl sulfate-polyacrylamide gel electrophoresis of virion preparations yielded a single prominent protein species of approximately 28,000 molecular weight; however, denaturing agarose gel electrophoresis showed that virions contained three prominent single-stranded RNAs of approximately 5.6, 4.2, and $2.8 \mathrm{~kb}$. Northern hybridization analyses, using transcripts generated from cloned cDNAs that corresponded to each of the virion RNAs, showed that the 5.6- and 4.2-kb RNAs were the genomic RNAs of the carrot red leaf luteovirus (CRLV) and the carrot mottle umbravirus $(\mathrm{CMoV})$, respectively. Virions also contained an approximately $1.3-\mathrm{kb}$ RNA related to the CMoV genomic RNA. The $2.8-\mathrm{kb}$ RNA did not hybridize with CRLV or CMoV cRNA probes. Analysis of
\end{abstract}

ABSTRACT naturally infected carrot (Daucus carota) plants showed that CRLV, $\mathrm{CMoV}$, and the 2.8-kb RNA were always present in carrot motley dwarfaffected plants. Greenhouse aphid- and mechanical-transmission experiments showed that the 2.8-kb RNA was consistently present in plants also infected by both CRLV and CMoV, but never in plants infected by only $\mathrm{CMoV}$. Near full-length cloned cDNAs corresponding to the $2.8 \mathrm{-kb}$ RNA were prepared, and the complete nucleotide sequence was determined to be 2,835 nucleotides. Two large open reading frames (ORFs), 1a and $1 \mathrm{~b}$, were present within the sequence and were separated by an amber (UAG) stop codon. A third ORF (ORF 2), capable of encoding a protein of 4,289 molecular weight, was located near the $3^{\prime}$ terminus. BLASTP results showed that the 2.8-kb RNA was most closely related to the beet western yellows luteovirus (BWYV) ST9-associated RNA. Based on its biological and molecular characteristics, we have named the 2.8-kb RNA the CRLV-associated RNA (CRLVaRNA).

Additional keywords: helper-dependent aphid-transmitted virus complex, transcapsidation.
Carrot motley dwarf (CMD) is a viral disease complex that affects carrots (Daucus carota L.) and other members of the family Umbelliferae (17,19,25-27,31-34). CMD is found wherever carrots are grown under cool climatic conditions $(25,32,34)$, and since first being described in 1956, has caused sporadic but severe losses in the Salinas Valley of California (27). Previous work has shown European CMD to be caused by two unrelated viruses: the carrot red leaf luteovirus (CRLV) and the carrot mottle umbravirus $(\mathrm{CMoV})(7,17,19,31)$. CRLV is transmitted in a circulative nonpropagative manner by Cavariella aegopodii Scop., the willowcarrot aphid $(7,26,31,32)$. CRLV virions are isometric, approximately $25 \mathrm{~nm}$ in diameter (30), and contain a prominent capsid protein of approximately 25,000 molecular weight (MW) (30) and a single-stranded genomic RNA of approximately $5.6 \mathrm{~kb}$ (19). $\mathrm{CMoV}$ is mechanically transmissible to plants; however, it is also aphid transmissible, but only when $\mathrm{CMoV}$ coinfects plants with CRLV, as in the CMD complex $(7,31,32)$. The CMoV RNA is separately encapsidated in capsids composed of CRLV proteins (transcapsidation), which most likely facilitates its aphid transmission along with CRLV $(7,19)$. The approximately 4.2-kb CMoV genomic RNA does not encode a capsid protein, but encodes proteins that facilitate $\mathrm{CMoV}$ replication and cell-to-cell movement (11).

In this paper, we report the characterization of the etiological agents involved in the CMD complex in California. In addition to CRLV and CMoV, plants infected by the California CMD viruses

Corresponding author: B. W. Falk; E-mail address: bwfalk@ucdavis.edu

Publication no. P-1997-1223-02R

(C) 1998 The American Phytopathological Society also contain a third RNA not described previously. This third RNA possesses molecular and biological properties similar to those of the beet western yellows luteovirus ST9-associated RNA (BWYV ST9aRNA), and we propose to name it the CRLV-associated RNA (CRLVaRNA).

\section{MATERIALS AND METHODS}

Virus and insect vector maintenance. Isolates of the California CMD viruses and Cavariella aegopodii were maintained as described $(33,34)$. Cilantro (Coriandrum sativum L.) and chervil (Anthriscus cerefolium (L.) Hoffm.) plants infected with the CMD viruses were harvested 17 to 21 days postinoculation and used for virion purification. Virions were purified using slight modifications of standard luteovirus virion purification protocols $(4,10,30)$. After rate-zonal sucrose density gradient centrifugation, the virion fractions were collected and the virions were pelleted by centrifugation in a Beckman 70 Ti rotor (Beckman Instruments, Inc., Palo Alto, CA) at $380,000 \times g$ for $1 \mathrm{~h}$. Pellets were resuspended in TE (0.01 M Tris-HCl, pH 7.4, and $1 \mathrm{mM}$ EDTA) and used for subsequent analysis. Virions of BWYV ST9 were also purified as before $(8,10)$.

Virion and RNA analysis. Purified virions were analyzed by sodium dodecyl sulfate-polyacrylamide gel electrophoresis (SDSPAGE) as described by Laemmli (15). Proteins were detected by staining with Coomassie brilliant blue and examination under visible light. RNAs were extracted from purified virions in $0.1 \mathrm{M}$ Tris-HCl, pH 8.0, 5 mM EDTA, and 1.5\% SDS. The solution was incubated at room temperature for $30 \mathrm{~min}$ and extracted twice with an equal volume of phenol/chloroform $(1: 1 \mathrm{vol} / \mathrm{vol})$ and once 
with chloroform. The RNAs were ethanol-precipitated and resuspended in sterile distilled water. Total RNAs from healthy and virus-infected plants were extracted as described previously $(5,8)$. RNAs were analyzed by glyoxal denaturing agarose gel electrophoresis (1\% agarose in $20 \mathrm{mM} \mathrm{N}$-2-hydroxyethylpiperazine- $N^{\prime}$ 2-ethanesulfonic acid and $1 \mathrm{mM}$ EDTA, pH 7.0) $(8,10,16)$. After electrophoresis, RNAs were detected by staining with ethidium bromide followed by UV (302 $\mathrm{nm}$ ) transillumination.

Virion and total RNAs were analyzed by Northern blot hybridization. RNAs were separated by denaturing agarose gel electrophoresis and then transferred by capillary blotting in 10× SSC (1× $\mathrm{SSC}$ is $0.15 \mathrm{M} \mathrm{NaCl}$ plus $0.015 \mathrm{M}$ sodium citrate) overnight to Hybond-N membranes (Amersham Corp., Arlington Heights, IL). The membranes were baked at $80^{\circ} \mathrm{C}$ for $2 \mathrm{~h}$ and stored in sealed plastic bags until used for hybridization.

cDNA cloning and analysis. Virion RNAs were polyadenylated as described (12) and used as templates for cDNA synthesis and subsequent cloning using the Superscript Plasmid System cDNA Synthesis and Cloning Kit (BRL, Gaithersburg, MD). Following ligation, the plasmids were transformed into MAX efficiency competent DH5 $\alpha$ Escherichia coli cells (BRL). Recombinant plasmids were identified and sizes of cDNA inserts determined by digestion with $M l u \mathrm{I}$ followed by agarose gel electrophoresis (1\% agarose in TAE [Tris-acetate-EDTA]). Overlapping inserts were subsequently confirmed by Southern blot analysis (24). The 2.8-kb RNA 5'terminal nucleotide sequence was determined by directly sequencing the RNA and by generating cDNA clones corresponding to $5^{\prime}$ terminus. The oligonucleotide primer CMDRNASEQ (5'ACTAGCGACTCGATGTC-3') was used to sequence the RNA directly (3). Clones corresponding to the $5^{\prime}$ terminus were obtained from virion RNAs using cDNAs primed with the oligonucleotide CMD-13 (5'-CGTCCTCTATACAG-3'). The resulting cDNAs were G-tailed and amplified by polymerase chain reaction (PCR) (12) using the oligonucleotide primers CMD-13 and BG07 $\left(5^{\prime}\right.$-GAGCTCGGATC $\left.(10)^{-} 3^{\prime}\right)$. Resulting PCR products were cloned into pGEM-T (Promega Corp., Madison, WI), following the manufacturer's protocol. We also attempted to obtain full-length cDNA clones corresponding to the 2.8 -kb RNA by priming cDNA synthesis with oligonucleotide primer CMD-1 (5'-ATAAGAATGCG-

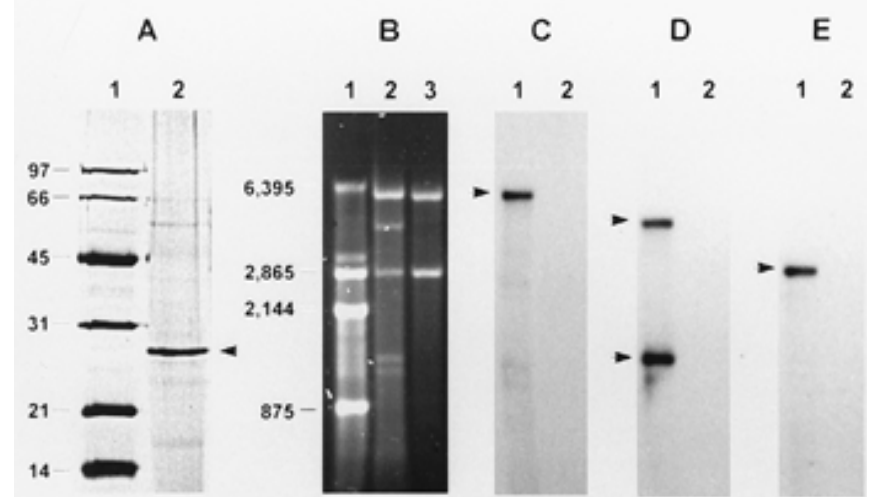

Fig. 1. Analysis of the protein and RNA composition of virions purified from carrot motley dwarf (CMD)-affected chervil plants. A, Sodium dodecyl sulfate-polyacrylamide gel showing virion proteins. Lane 1, Molecular weight markers and numbers at left indicate molecular weights $\left(\times 10^{-3}\right)$. Lane 2 , Proteins from CMD virions. Arrow at right shows position of approximately 28,000 molecular weight capsid protein. B, Denaturing agarose gel electrophoresis analysis of CMD virion RNAs. Lane 1, RNA markers and numbers at left indicate sizes (in nucleotides) of marker RNAs. Lanes 2 and 3, Virion RNAs for CMD and beet western yellows virus ST9, respectively. C, D, and $\mathbf{E}$, Results of Northern blot analysis of identical RNA samples to those of $\mathbf{B}$, lanes 2 and 3. C, Samples probed with transcripts from the carrot red leaf virus cDNA clone 128. D, Samples probed with transcripts from the carrot mottle virus cDNA clone 148. E, Samples probed with transcripts from the 2.8-kb RNA cDNA clone a25. Arrows to the left of $\mathbf{C}, \mathbf{D}$, and $\mathbf{E}$ indicate positions of positive hybridization signals for the respective probes.
GCCGCGGGCGGGGTTCCTGGTAATCCGAA-3', containing 24 nucleotides [underlined] complementary to the 2.8 -kb RNA 3' terminus [details in Results]; nucleotides shown in italics represent a NotI site for cloning). Second-strand synthesis and cloning were done using the Superscript Plasmid System (BRL), as described above.

Selected plasmids corresponding to each RNA were used to generate probes for use in RNA and dot-blot hybridization assays. Plasmids were digested with SalI, and digoxigenin-11-UTP-labeled transcripts (DIG-labeled transcripts) were generated using SP6 RNA polymerase and the Genius 4 RNA Labeling Kit (Boehringer Mannheim, Indianapolis, IN), except that each reaction also contained 20 units of RNasin (Promega Corp.). Hybridization reactions were done overnight at 55 to $62^{\circ} \mathrm{C}$ with 10 to $30 \mathrm{ng}$ of DIG-labeled transcript per milliliter of hybridization solution. Blots were washed, and hybridization reactions were detected using CDP Star as described in the Genius System Users' Guide (Boehringer Mannheim).

Nucleotide sequence analyses. Nucleotide sequences of selected cloned cDNAs were determined by dideoxynucleotide se-
A

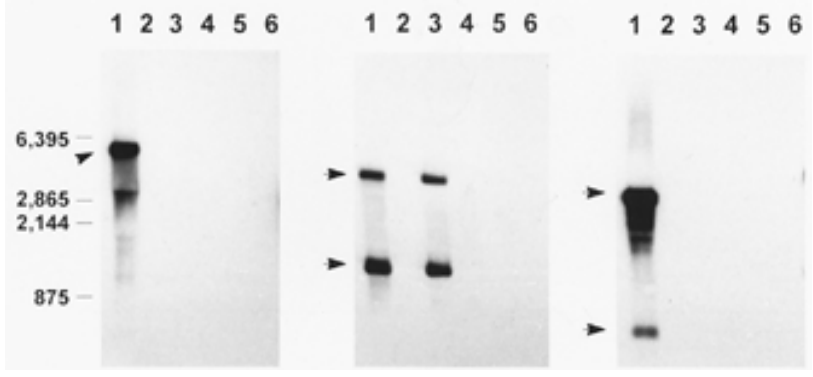

Fig. 2. Northern blot analysis of total RNAs extracted from plants infected with the carrot motley dwarf (CMD) viruses. RNAs were separated by denaturing agarose gel electrophoresis and transferred to Hybond-N membranes, followed by hybridization analysis. Samples are total RNAs extracted from lane 1, CMD-affected chervil plants; lane 2, healthy chervil; lane 3, Nicotiana benthamiana plants mechanically inoculated from CMD-affected chervil; lane 4 , healthy $N$. benthamiana plants; lane 5 , beet western yellows virus ST9-infected Capsella bursa-pastoris plants; and lane 6, healthy Capsella bursa-pastoris plants. A, Results of hybridization analysis using transcripts from the carrot red leaf virus (CRLV) cDNA clone 128. Numbers to the left indicate positions of RNA markers and sizes in nucleotides. Arrow to the left indicates the position of the CRLV genomic RNA. B, Samples were probed with transcripts from the carrot mottle virus $(\mathrm{CMoV})$ cDNA clone 148. Arrows to the left indicate positions of the $\mathrm{CMoV}$ genomic (upper arrow) and putative subgenomic (lower arrow) RNAs. C, Samples were probed with transcripts from the 2.8-kb RNA cDNA clone a25. Arrows to the left indicate positions of the 2.8-kb RNA (upper arrow) and the highly abundant putative subgenomic RNA (lower arrow).

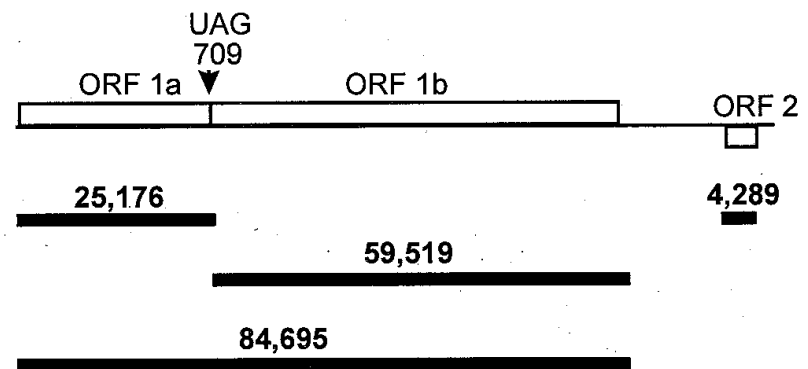

\begin{tabular}{rrrrrrr}
0 & 500 & 1,000 & 1,500 & 2,000 & 2,500 & 3,000 \\
\hline
\end{tabular}

Fig. 3. Proposed genomic map of the 2.8-kb RNA. Open boxes indicate open reading frames (ORFs). ORFs $1 \mathrm{a}$ and $1 \mathrm{~b}$ are separated by an amber (UAG) termination codon at nucleotide positions 709 to 711 . Bars below the map indicate possible protein products, and numbers indicate molecular weights of respective putative proteins. Scale in nucleotides is indicated at the bottom. 
quence analysis $(12,22)$ using the Sequenase kit (United States Biochemical Corp., Cleveland). The nucleotide sequence and deduced amino acid sequences were compared with similar sequences by using BLASTN and BLASTP and the nonredundant sequence database at the National Center for Biotechnology Information (NIH) $(1,2)$. Further comparisons were done using Gap from the University of Wisconsin Genetics Computer Group (GCG) package (6).

\section{RESULTS}

Virion and RNA analysis. Virions sedimented as a single component in rate-zonal sucrose gradients. SDS-PAGE analysis of purified virions showed a single predominant virion protein of ap- proximately 28,000 MW and lesser amounts of a protein of approximately 55,000 MW (Fig. 1A). However, analysis of virion RNAs by denaturing agarose gel electrophoresis showed virions to contain three abundant RNAs of approximately 5.6, 4.2, and $2.8 \mathrm{~kb}$ (Fig. 1B, lane 2). Two smaller, less abundant RNAs were also visible (Fig. 1B). The approximately 5.6- and 4.2-kb RNAs corresponded in size with those previously identified for CRLV and CMoV, respectively $(11,19)$. No RNA similar in size to the approximately $2.8 \mathrm{-kb}$ RNA has previously been reported to be associated with CMD or with virions from CMD-affected plants. In our experiments, the approximately 2.8 -kb RNA was always associated with virions purified from CMD-affected plants. Because the three CMD-associated RNAs represent a virus complex, we

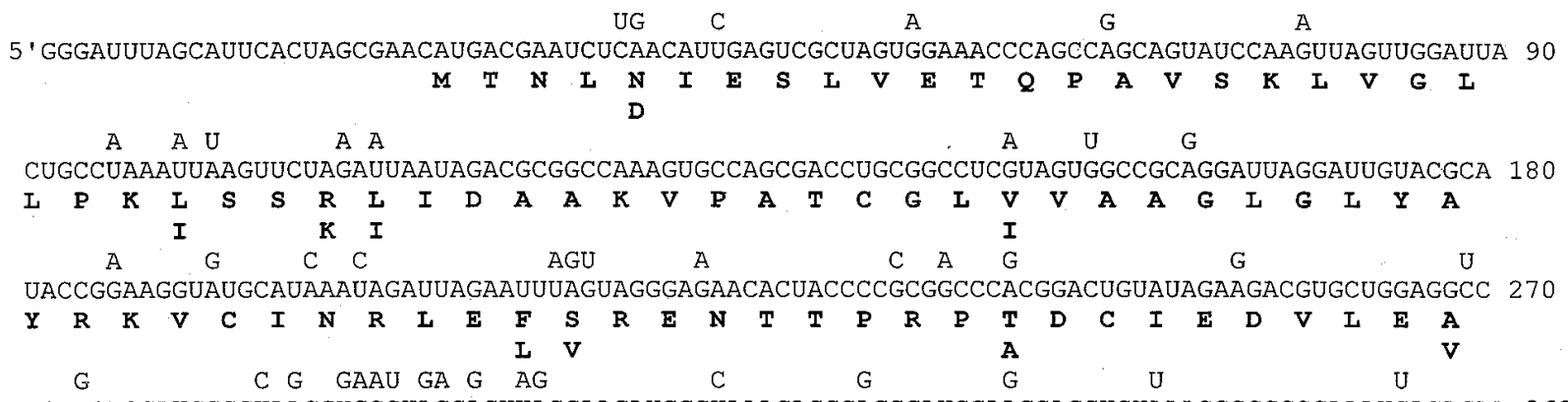

Fig. 4. The complete nucleotide sequence of the 2.8 -kb RNA. The primary nucleotide sequence shown is a25. Nucleotide changes for a8 are shown above the a25 sequence. Numbers at right indicate nucleotide position from the $5^{\prime}$ terminus. The deduced amino acid sequences corresponding to the respective open reading frames are shown as bold letters, using the single letter amino acid code. The primary amino acid sequences correspond to a25, while changes resulting from nucleotide changes in the a8 sequence are indicated below the amino acid sequence deduced from a25. Horizontal lines numbered I to VIII (italicized) indicate the eight motifs characteristic of positive-sense single-stranded RNA virus RNA-dependent RNA polymerases (14). 
compared them by agarose gel electrophoresis with the virion RNAs of another luteovirus complex, the BWYV ST9 virion RNAs (8, 10). In side-by-side comparisons, the electrophoretic mobility of the CMD-associated 5.6-kb RNA was similar to that of the BWYVST9 genomic RNA, and the 2.8-kb RNA had an electrophoretic mobility very similar to that of the BWYV ST9aRNA (Fig. 1B).

To determine the nature and relationships of the CMD-associated RNAs, cDNA clones were generated to the CMD virion RNAs. No detectable cDNA synthesis resulted using an oligo dT primer. However, cDNA synthesis was efficient using RNAs that were polyadenylated in vitro, and approximately 400 recombinant plasmids were obtained. One hundred seventy-five clones were screened and contained cDNA inserts ranging in size from 300 to over 2,000 nucleotides. Fifty-six clones were used to generate DIGlabeled cRNA transcripts. The transcripts were used as probes for Northern hybridization experiments with CMD virion RNAs and total RNAs from CMD-affected plants. Transcripts from 28 clones specifically hybridized with the approximately $2.8-\mathrm{kb}$ RNA, 27 hybridized with the approximately 5.6-kb RNA, and transcripts from one clone (clone 148) hybridized with the approximately $4.2-\mathrm{kb}$

Fig. 4. (continued from the preceding page)

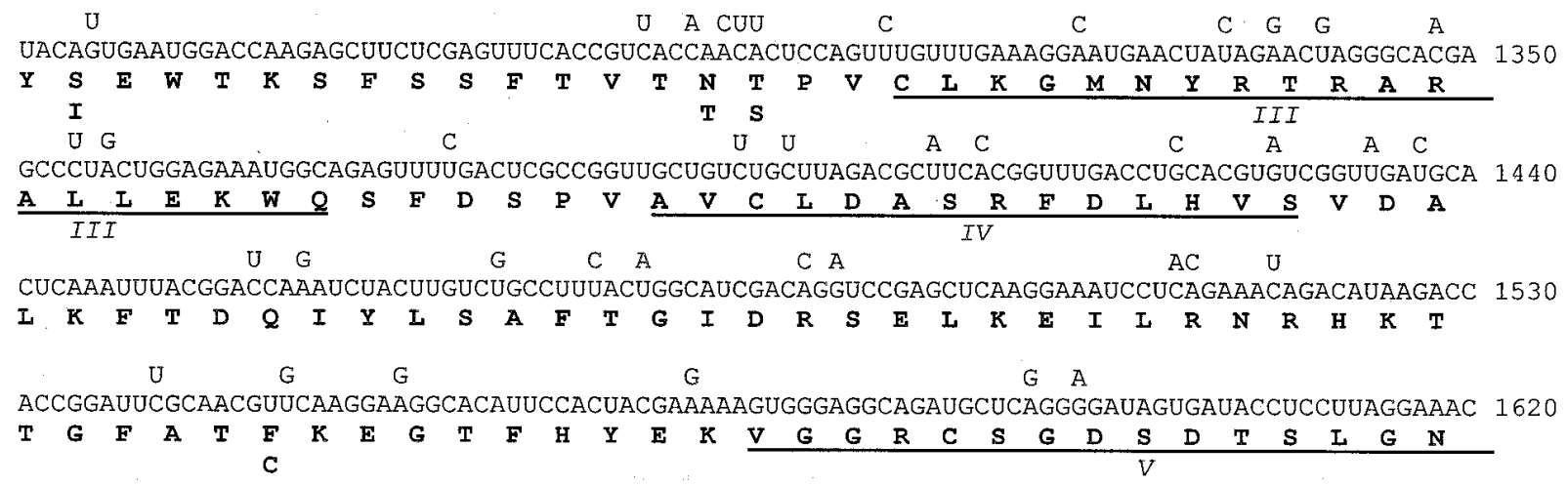

U $A$ G GC G AG A

$\mathrm{U}$

GUGAGCAUCAUGCUGGCAAUCACAAGGGUGAUUUGUGAAGGACUGAAAGGCAUACACAUUGAAGUAGCCAAUGAUGGAGAUGACCAGGUG 1710

\begin{tabular}{llllllllllllllllllllllllllllllllll}
$\mathbf{V}$ & $\mathbf{S}$ & $\mathbf{I}$ & $\mathbf{M}$ & $\mathbf{L}$ & $\mathbf{A}$ & $\mathbf{I}$ & $\mathbf{T}$ & $\mathbf{R}$ & $\mathbf{V}$ & $\mathbf{I}$ & $\mathbf{C}$ & $\mathbf{E}$ & $\mathbf{G}$ & $\mathbf{L}$ & $\mathbf{K}$ & $\mathbf{G}$ & $\mathbf{I}$ & $\mathbf{H}$ & $\mathbf{I}$ & $\mathbf{E}$ & $\mathbf{V}$ & $\mathbf{A}$ & $\mathbf{N}$ & $\mathbf{D}$ & $\mathbf{G}$ & $\mathbf{D}$ & $\mathbf{D}$ & $\mathbf{Q}$ & $\mathbf{V}$ & \\
\hline $\mathrm{C}$ & & & & & $\mathrm{V}$ & & & & & & & & & $\mathbf{E}$ & & & & & & & & & & & & & & $V I$ & & & &
\end{tabular}

UUGAUGGUCGAGACAAACCAACUCGACAACCUGGUCAAGGAGCUUAGUCCCACAUUCGCGCGAUUUGGUUUUCGCGUGAAAGUAGAGGAU 1800

$\begin{array}{lllllllllllllllllllllllllllllll}\mathbf{L} & \mathbf{M} & \mathbf{V} & \mathbf{E} & \mathbf{T} & \mathbf{N} & \mathbf{Q} & \mathbf{L} & \mathbf{D} & \mathbf{N} & \mathbf{L} & \mathbf{V} & \mathbf{K} & \mathbf{E} & \mathbf{L} & \mathbf{S} & \mathbf{P} & \mathbf{T} & \mathbf{F} & \mathbf{A} & \mathbf{R} & \mathbf{F} & \mathbf{G} & \mathbf{F} & \mathbf{R} & \mathbf{V} & \mathbf{K} & \mathbf{V} & \mathbf{E} & \mathbf{D}\end{array}$

A A $\quad$ G $\quad$ G C

CCUGUCUGGGAAUUCGAGAgAAUAGAUUUUUGCCAAACCAGACCGAUCUUCCUAUCACCAGGUGAGCCCAUAAUGUGCCGAUACCCAAUG 1890

\begin{tabular}{lllllllllllllllllllllllllllllll}
$\mathbf{P}$ & $\mathbf{V}$ & $\mathbf{W}$ & $\mathbf{E}$ & $\mathbf{F}$ & $\mathbf{E}$ & $\mathbf{R}$ & $\mathbf{I}$ & $\mathbf{D}$ & $\mathbf{F}$ & $\mathbf{C}$ & $\mathbf{Q}$ & $\mathbf{T}$ & $\mathbf{R}$ & $\mathbf{P}$ & $\mathbf{I}$ & $\mathbf{F}$ & $\mathbf{L}$ & $\mathbf{S}$ & $\mathbf{P}$ & $\mathbf{G}$ & $\mathbf{E}$ & $\mathbf{P}$ & $\mathbf{I}$ & $\mathbf{M}$ & $\mathbf{C}$ & $\mathbf{R}$ & $\mathbf{Y}$ & $\mathbf{P}$ & $\mathbf{M}$ \\
\hline
\end{tabular}

A A $A$

CAGUCUAUGUCCAAAGACGUUGCGUCCUUCCUCAAUAUAGAAAGAUCAGAGGGAUGGAAAUACAUGCUCAGAGCUAUAGGAGCAUGUGGG 1980

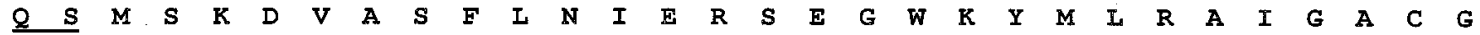

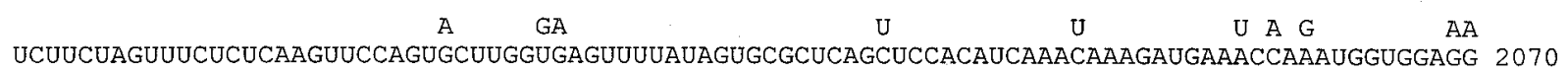

$\begin{array}{lllllllllllllllllllllllllllllll}\mathbf{S} & \mathbf{S} & \mathbf{S} & \mathbf{F} & \mathbf{S} & \boldsymbol{Q} & \mathbf{V} & \mathbf{P} & \mathbf{V} & \mathbf{L} & \mathbf{G} & \mathbf{E} & \mathbf{F} & \mathbf{Y} & \mathbf{S} & \mathbf{A} & \mathbf{L} & \mathbf{S} & \mathbf{S} & \mathbf{T} & \mathbf{S} & \mathbf{N} & \mathbf{K} & \mathbf{D} & \mathbf{E} & \mathbf{T} & \mathbf{K} & \mathbf{W} & \mathbf{W} & \mathbf{R} \\ \mathbf{R} & & & \end{array}$

A C G C A GTGG G GAT T C

CGCACGGGAgUUGAUUUGGGGUUUAAACAGCUUACCAACAAUGUAGGCACGAUCCCUUACGACGAGGUCACGGCACGAAGCUCCUUCUAU 2160

$\begin{array}{llllllllllllllllllllllllllllll}R & T & G & V & D & I & G & \mathbf{F} & \mathbf{K} & \boldsymbol{Q} & \mathbf{L} & \mathbf{T} & \mathbf{N} & \mathbf{N} & \mathbf{V} & \mathbf{G} & \mathbf{T} & \mathbf{I} & \mathbf{P} & \mathbf{Y} & \mathbf{D} & \mathbf{E} & \mathbf{V} & \mathbf{T} & \mathbf{A} & \mathbf{R} & \mathbf{S} & \mathbf{S} & \mathbf{F} & \mathbf{Y}\end{array}$

Q U $\quad$ S $\mathbf{G}$ D GAA CA U

AAGGCCUUCGGAAUCCUCCCAGACACCCAAGCAGCACUCGAAAGCAAAAUACGCAACUGGAAUAUGAGCUCCGUACCACACAUCGAGCAA 2250

$\begin{array}{llllllllllllllllllllllllllllll}\mathbf{K} & \mathbf{A} & \mathbf{F} & \mathbf{G} & \mathbf{I} & \mathbf{L} & \mathbf{P} & \mathbf{D} & \mathbf{T} & \mathbf{Q} & \mathbf{A} & \mathbf{A} & \mathbf{L} & \mathbf{E} & \mathbf{S} & \mathbf{K} & \mathbf{I} & \mathbf{R} & \mathbf{N} & \mathbf{W} & \mathbf{N} & \mathbf{M} & \mathbf{S} & \mathbf{S} & \mathbf{V} & \mathbf{P} & \mathbf{H} & \mathbf{I} & \mathbf{E} & \mathbf{Q}\end{array}$

A TTA AGT AG TG T AGT A G CTTC

GUCCACAAAUUCUCGAGUGAGUUUCCCGUGGUUGACGGAUGGGCCUAACUUAGGGAAUACAGUUAGGUUAAGUUAGUCGGCCCCUCCUCU 2340 $\begin{array}{lllllllllllllllll}\mathbf{V} & \mathbf{H} & \mathbf{K} & \mathbf{F} & \mathbf{S} & \mathbf{S} & \mathbf{E} & \mathbf{F} & \mathbf{P} & \mathrm{V} & \mathrm{V} & \mathbf{D} & \mathbf{G} & \mathbf{W} & \mathbf{A} & \text { * }\end{array}$

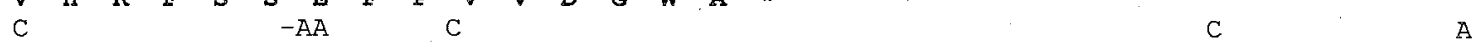
UGCUGGCUGGGUGAGAgGGGGGGCCAGCGCAGACUGGUUGGAUAGGUUUGGGAACAUAGAUCCGAACUCCAAUCAACGGGUAGGUCGCAC 2430 $\begin{array}{ccccc}\text { G } & C & U & U & \text { A }\end{array}$ CCGCGUAGUCGAGAAUGAUUACCAUAAUUGGUAGGUGAGGUCACGCCGUAUGGCCAAGUCACCCGAGCUUUCGGUAGGGGGUCUAUUGU 2520 UU G G CG GA C $\quad$ G A UGAGUGCCAUUAUGACAUAACCAACUAGACACCCCACAUUUGGAGAAGCGGCUUGCCCACGCUCCAȦAUUCCAUGGAUAGAUUGAACGA 2610

$\mathrm{GA} \quad \mathrm{GC}$

CGAAAUGUCAUUGUCUUGCCGUCAGAGGCGUUCCCCUCUCCAAGGCUAGCCCGACGUGCGCCAUGCUUGGGGUCUAUGGAAUAGUUGAUG 2700

$\begin{array}{lllllllllll}M & \mathbf{L} & G & \boldsymbol{V} & \mathbf{Y} & \mathbf{G} & \mathbf{I} & \mathbf{V} & \mathbf{D} & \mathbf{G}\end{array}$

GUGGGAACUACAGGGGAGGGUAUGCCCCAAGCUAUUACCCAAGUGUGAAACUCCCGCACGACACCACUUCGAAGCCGGAGUGGGGGCGUU 2790

$\begin{array}{lllllllllllllllllllllllllllllll}\mathbf{G} & \mathbf{N} & \mathbf{Y} & \mathbf{R} & \mathbf{G} & \mathbf{G} & \mathbf{Y} & \mathbf{A} & \mathbf{P} & \mathbf{S} & \mathbf{Y} & \mathbf{Y} & \mathbf{P} & \mathbf{S} & \mathbf{V} & \mathbf{K} & \mathbf{L} & \mathbf{P} & \mathbf{H} & \mathbf{D} & \mathbf{T} & \mathbf{T} & \mathbf{S} & \mathbf{K} & \mathbf{P} & \mathbf{E} & \mathbf{W} & \mathbf{G} & \mathbf{R} & \text { * }\end{array}$ 
RNA (Fig. 1C, D, and E). Similarly, a cDNA clone (clone 369, kindly provided by M. Gibbs) to an Australian isolate of $\mathrm{CMoV}$ hybridized with the 4.2-kb RNA (data not shown). Northern hybridization analyses of total RNAs from plants infected with the CMD viruses gave results similar to those for virion RNAs, except that smaller RNAs were also identified (Fig. 2). The probes for the 4.2-kb RNA also hybridized to a smaller RNA of approximately $1.3 \mathrm{~kb}$ (Fig. 2B), and probes to the $2.8-\mathrm{kb}$ RNA hybridized with an approximately $0.7-\mathrm{kb}$ RNA (Fig. 2C), suggesting that these may represent subgenomic RNAs. BWYV ST9 virion RNAs and total RNAs also were used in these analyses. No hybridization was observed when the above transcripts were used to probe BWYV ST9 virion (Fig. 1C, D, and E) or total RNAs (Fig. 2). Similarly, when transcripts were generated from cloned cDNAs to the BWYV ST9 genomic RNAs, positive hybridization signals were obtained only for the homologous RNA (i.e., BWYV transcripts hybridized with BWYV genomic RNA; data not shown). Thus, the CMD virion RNAs are distinct from those of the BWYV ST9 complex. Furthermore, based on the observed hybridization patterns and the sizes of the CRLV and CMoV genomic RNAs $(11,19)$, our data suggest that the approximately 5.6and 4.2-kb RNA represent the genomic RNAs of CRLV and $\mathrm{CMoV}$, respectively. The 2.8-kb RNA is distinct from the CRLV and CMoV RNAs and represents a third RNA associated with California CMD.

Association of the approximately 2.8-kb RNA with CRLV. To understand the association of the 2.8-kb RNA with CRLV and $\mathrm{CMoV}$, we used aphid and mechanical transmission to infect differential indicator plants as a means to partially separate the different viral RNAs. Aphid and mechanical inoculations were done

TABLE 1. BLASTN and BLASTP comparisons of the 2.8-kb RNA nucleotide and deduced amino acid sequences

\begin{tabular}{lll}
\hline Virus & \multicolumn{1}{c}{$P$} & \multicolumn{1}{c}{ Sequence $^{\mathrm{a}}$} \\
\hline BLASTN $^{\mathrm{b}}$ (2.8-kb RNA) & & \\
BWYV ST9aRNA & $3.9 \times e^{-40}$ & Complete genome \\
CNV & 0.00031 & Complete genome \\
CMoV-A & 0.0015 & Complete genome \\
TNV-A & 0.047 & RdRP + CP region \\
PEMV & 0.057 & RdRP + CP region \\
BLASTP (ORF 1a) & & \\
BWYV ST9aRNA & $1.9 \times e^{-31}$ & ORF 1a \\
OLV & 0.00026 & ORF 1 \\
OLV & 0.00039 & RdRP \\
TNV A & 0.0099 & RdRP \\
MCV & 0.19 & ORF 1 \\
BLASTP (ORF 1b) & & \\
BWYV ST9aRNA & $9.7 \times e^{-116}$ & ORF 1b \\
TNV A & $4.5 \times e^{-68}$ & RdRP \\
OLV & $2.3 \times e^{-65}$ & RdRP \\
CarMV & $1.3 \times e^{-62}$ & RdRP \\
TNV D & $1.8 \times e^{-59}$ & RdRP \\
\hline Access number for &
\end{tabular}

a Accession numbers for sequences used are BWYV ST9aRNA, L04281; CNV, M25270; CMoV-A, U57305; TNV A, M33002; PEMV, U03563; OLV, X85989; MCV type 1, L10127; CarMV, P04518; and TNV, D P27209.

${ }^{\mathrm{b}}$ BLASTN = comparisons of the complete carrot red leaf virus-associated RNA (CRLVaRNA) nucleotide sequence (clone a25) with the most similar designated nucleotide sequences from existing databases. BWYV ST9aRNA $=$ the beet western yellows luteovirus ST9 associated RNA; CNV $=$ the cucumber necrosis tombusvirus; $\mathrm{CMoV} \mathrm{A}=$ the carrot mottle umbravirus, strain $\mathrm{A} ; \mathrm{TNV} \mathrm{A}=$ the tobacco necrosis necrovirus, strain $\mathrm{A}$; and $\mathrm{PEMV}=$ the pea enation mosaic enamovirus RNA 2. RdRP $=$ RNA-dependent RNA polymerase and $\mathrm{CP}=$ coat protein.

${ }^{c}$ BLASTP $=$ comparisons of the CRLVaRNA indicated amino acid sequences (ORF 1a and ORF $1 \mathrm{~b}$ derived from clone a25) with the most similar designated amino acid sequences from existing databases. BWYV ST9aRNA is described under BLASTN. OLV = the olive latent necrovirus; TNV $\mathrm{A}=$ the tobacco necrosis necrovirus, strain $\mathrm{A} ; \mathrm{MCV}=$ Molluscum contagiosum virus type 1 ; TNV D = the tobacco necrosis necrovirus, strain D; and CarMV = the carnation mottle carmovirus. RdRP $=$ RNA-dependent RNA polymerase. from CMD-affected chervil or carrot plants to carrot, chervil, $C$. sativum, Nicotiana clevelandii, and $N$. benthamiana plants. The latter two plants are not hosts for CRLV, but are hosts for CMoV (32; B. W. Falk and T. Tian, unpublished data). Total and dsRNAs (29) were extracted from test plants and analyzed by agarose gel electrophoresis, followed by Northern hybridization as a means to identify specific RNAs. The 2.8-kb RNA, as well as CRLV and $\mathrm{CMoV}$, were always detected in total RNAs from aphid-inoculated chervil, carrot, and C. sativum plants. However, only $\mathrm{CMoV}$ was detected in mechanically inoculated $N$. clevelandii, $N$. benthamiana, and C. sativum plants (Fig. 2A, B, and C, lane 3). When Cavariella aegopodii aphids were used to transmit viruses from CMD-affected carrot to $N$. benthamiana plants, the aphidinoculated $N$. benthamiana plants contained only $\mathrm{CMoV}$, identical to results obtained in the mechanical-transmission experiments (data not shown). Thus, the 2.8-kb RNA was unable to systemically infect plants that contained CMoV but not CRLV.

Nucleotide sequence analysis and comparison with the BWYV ST9aRNA. Because of its association with CRLV and the similarity in size to the BWYV ST9aRNA $(2,844$ nucleotides) $(3,21)$, we assessed by nucleotide sequence analysis whether the 2.8 -kb RNA was related to the BWYV ST9aRNA. We determined the complete nucleotide sequence for the 2.8-kb RNA and compared its nucleotide sequence and the deduced amino acid sequences of specific open reading frames (ORFs) with those available in databases.

Initial nucleotide sequence analyses of six clones showed that all contained an identical 3 '-terminal nucleotide sequence and terminated with CCC. To obtain near full-length cDNA clones, we used a primer (CMD-1) complementary to the 3'-terminal $24 \mathrm{nu}$ cleotides and synthesized new cDNAs from virion RNAs. Twentyfour cDNA clones were compared by agarose gel electrophoresis. The two largest, a 8 and a25, were sequenced completely in both directions and shown to be 2,808 and 2,817 nucleotides, respectively. Two approaches were used to determine whether either contained the 2.8-kb RNA 5' terminus. First, the 2.8-kb RNA 5' terminus was directly sequenced from virion RNA, and second, reverse transcription-PCR clones corresponding to the $5^{\prime}$ terminus were generated and sequenced. Both methods showed an identical sequence for the $5^{\prime}$ region and revealed that clones a8 and a25 lacked 26 and 18 nucleotides, respectively, from the $5^{\prime}$ terminus.

Comparison of the nucleotide sequences for clones a8 and a25 using Gap showed a high amount of nucleotide sequence variability. There were 280 nucleotide substitutions scattered throughout the sequence and one insertion/deletion at nucleotide position 2,357 . The overall nucleotide sequence identity between the two clones was $90 \%$. To confirm the nucleotide changes between a8 and a25, two additional cDNA clones (a23 and a43) were analyzed. Greater than $90 \%$ of the nucleotide sequences for each of these clones were determined. Interestingly, clone a23 had a nucleotide sequence almost identical to a8, but lacked 163 nucleotides from the $5^{\prime}$ terminus. Clone a43 corresponded to a25, but lacked 483 nucleotides from the $5^{\prime}$ terminus. Maps of possible ORFs deduced from nucleotide sequences of a8 and a25 were identical, each containing three ORFs, designated $1 \mathrm{a}, 1 \mathrm{~b}$, and 2 (Fig. 3). Because of the insertion/deletion at nucleotide 2,357, the intergenic sequence between ORFs 1 and 2 was 377 nucleotides for clone a 25 and 376 for clone a8. Thus, the complete nucleotide sequence of this RNA was 2,835 nucleotides, based on clone a25. Nucleotide sequences from both a8 and a25 are shown (Fig. 4) and were submitted to GenBank under accessions AF020616 and AF020617 for clones a8 and a25, respectively.

The nucleotide sequence variation resulted in a number of amino acid differences between the ORFs of a8 and a25, giving 22 amino acid differences for the ORF 1a region, 23 differences for the ORF $1 b$ region, and one difference for ORF 2. However, comparison of the amino acid sequences using Gap showed that the a8 and a25 ORFs 1a, 1b, and 2 were 95, 98, and 97\% similar, respectively. ORF 1a begins at nucleotide position 25 and is sepa- 
rated from ORF $1 b$ by an amber (UAG) termination codon located at nucleotides 709 to 711 . ORFs $1 \mathrm{a}$ and $1 \mathrm{~b}$ potentially encode proteins of 25,176 and 59,519 MW, respectively. However, the nucleotide sequence surrounding the UAG stop codon (AAAUAGGGG) was very similar to sequences flanking readthrough stop codons for other plant viruses including the BWYV ST9aRNA (AAA-

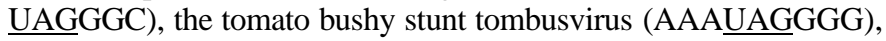
and the carnation mottle carmovirus (CarMV) (AAA $\overline{U A G G G G) ~}$ (3). Readthrough translation of ORFs 1a plus $1 \mathrm{~b}$ would yield a protein of 84,695 MW. We found no distinguishing motifs suggesting possible function(s) for the ORF 1a protein. Within the ORF 1b sequence, the eight motifs (14) conserved among RNAdependent polymerases were identified, suggesting that the ORF $1 \mathrm{~b}$ (more likely, the ORF $1 \mathrm{a}+1 \mathrm{~b}$ protein) is a RNA-dependent RNA polymerase. ORF 2 is located downstream, between nucleotides 2,673 and 2,790, and could potentially encode for a protein of 4,289 MW.

BLASTP comparisons of the deduced amino acid sequences with those of other proteins in the databases showed that the ORF 1a-encoded protein was significantly similar $\left(P=1.9 \times e^{-31}\right)$ to the ORF 1a-encoded protein of the BWYV ST9aRNA. The only other plant virus proteins showing detectable similarity with the $2.8-\mathrm{kb}$ ORF 1a-encoded protein were those of necrovirus ORF 1-encoded proteins (Table 1). Comparison of the ORF 1b-encoded protein also showed that it was most similar to the BWYV ST9aRNA ORF 1b-encoded protein $\left(P=9.7 \times e^{-116}\right)$. However, the ORF 1bencoded protein was significantly similar to RNA-dependent RNA polymerases encoded by several other plant viruses, including those of necroviruses and CarMV (Table 1). BLASTP searches for the ORF 2-encoded protein failed to identify any significant similarity to other proteins, including the putative protein encoded by the similarly positioned ORF 2 of the BWYV ST9aRNA.

BLASTN comparisons also showed that the 2.8-kb RNA was most similar to the BWYV ST9aRNA (Table 1). The overall nucleotide sequence identity between them was only $50 \%$ (using gap weight $=5$ and length weight $=0.1$ ). However, the $2.8-\mathrm{kb}$ RNA 5 -terminal eight nucleotides (GGGAUUUA) and the 3 '-terminal six nucleotides (CCGCCC) were identical to the corresponding nucleotides for the BWYV ST9aRNA (3).

\section{DISCUSSION}

Like work done previously with CMD in Europe and Australia $(7,17,19,31)$, we found that CRLV and CMoV are associated with California CMD. However, unlike previous reports, the California CMD-affected plants also contained a third RNA, the 2.8-kb RNA. Furthermore, the 2.8-kb RNA appears to be a primary component of CMD in California. Northern hybridization and double-stranded RNA analyses of all CMD-affected carrot plants collected by us between 1989 and 1997, as well as virus isolates maintained in our greenhouse, showed all three viral RNAs to be present in all CMD-affected plants (33; data not shown). This included over 95 separate CMD-affected carrot plants collected from three California carrot-growing regions: the coastal regions of Oxnard and the Salinas Valley, and the interior San Joaquin Valley. In a survey conducted in December 1993 in the Salinas Valley, dot-blot analysis of randomly collected carrot plants revealed that $63 \%$ of the plants tested contained all three CMD-associated RNAs (33). The remaining $37 \%$ of the carrot plants were not infected, and none contained any other combination of these RNAs. Thus, the widespread and abundant nature of the 2.8-kb RNA led us to investigate its molecular biology and relationship to other viral RNAs.

Computer-assisted sequence analysis indicated that the $2.8-\mathrm{kb}$ RNA associated with California CMD is very similar to the BWYV ST9aRNA. The original proposed genomic map of the ST9aRNA suggested a possible third ORF; however, recent nucleotide sequence analysis performed by us has identified an additional $U$ at position 1,188 giving a corrected genomic map nearly identical to that seen here for the 2.8-kb RNA (21). Thus, the BWYV
ST9aRNA and 2.8-kb RNA are similar in size, and their genome organizations, nucleotide, and deduced amino acid sequences exhibit a high degree of similarity. Furthermore, their $5^{\prime}$ and $3^{\prime}$ termini have identical nucleotide sequences. The ST9aRNA has been demonstrated to be dependent on BWYV for encapsidation (and likely subsequent aphid transmission and in planta systemic movement) $(10,20,23)$. Interestingly, the dependence of the BWYV ST9aRNA on its luteovirus helper, BWYV, is not for replication. The BWYV ST9aRNA alone is competent for replication. Based on their overall similarities and biologies and the RNA-dependent RNA polymerase motifs found within the ORF $1 \mathrm{~b}$-encoded protein, it is likely that the 2.8-kb RNA also is competent for replication.

We were unable to demonstrate unequivocally that the $2.8-\mathrm{kb}$ RNA was dependent for encapsidation and aphid transmission by only CRLV. In our experiments, plants containing the 2.8-kb RNA also contained CRLV and CMoV. We attempted to establish plants infected by only CRLV, or CRLV plus the $2.8-\mathrm{kb}$ RNA, but we were unable to do so. However, the 2.8 -kb RNA was not supported by $\mathrm{CMoV}$ in aphid- or mechanically inoculated $N$. benthamiana plants, suggesting that $\mathrm{CMoV}$ alone is not a suitable helper virus for the $2.8-\mathrm{kb}$ RNA. CMoV does not encode a capsid protein (11), further suggesting that the 2.8-kb RNA is dependent on CRLV for encapsidation. Based on the biology of the CMD complex and the overall similarities between the 2.8-kb RNA and the BWYV ST9aRNA, it seems highly likely that, like the BWYV ST9aRNA, the 2.8-kb RNA is dependent on CRLV for encapsidation and aphid transmission. Thus, we propose to name the $2.8-\mathrm{kb}$ RNA as the CRLVaRNA.

Our data suggest that all three genomic RNAs, CRLV, CMoV, and CRLVaRNA, are encapsidated separately in virions composed of CRLV capsid proteins. All three RNAs can be isolated from virions purified from CMD-affected plants, and these virions sediment in sucrose gradients as a single component similar in a position to that of BWYV virions, about $118 \mathrm{~S}$. This is somewhat analogous to other reports of CMD, in which CRLV and CMoV genomic RNAs are separately encapsidated in virions composed of CRLV capsid proteins $(19,30)$. Like CMoV (11), the CRLVaRNA does not encode a capsid protein and is encapsidated by CRLV capsid proteins.

Interestingly, a smaller approximately $1.3-\mathrm{kb} \mathrm{CMoV}$-related RNA was also detected by us in purified virions (Fig. 1C). This is likely a CMoV subgenomic RNA. It was detected by using probes corresponding to the 3' region of the $\mathrm{CMoV}$ genomic RNA. Furthermore, the genomic maps of $\mathrm{CMoV}$ and of the groundnut rosette umbravirus (GRV) show 3' ORFs that are believed to be translated via a subgenomic RNA $(11,28)$. A corresponding 1.3-kb subgenomic RNA that also maps to the $3^{\prime}$ region of the genome has been identified for GRV (28). Because virions sediment as a single component, it is likely they all contain similar amounts of RNA. Thus, the virions purified from CMD-affected plants are likely of three classes. One class contains the CRLV genomic RNA (5.6 kb). The second contains the $\mathrm{CMoV}$ genomic RNA plus the $\mathrm{CMoV}$ subgenomic RNA ( $4.2 \mathrm{~kb}$ plus $1.3 \mathrm{~kb}=5.5 \mathrm{~kb}$ ). The third class of virions likely contains two molecules of the CRLVaRNA ( $2.8 \mathrm{~kb}+$ $2.8 \mathrm{~kb}=5.6 \mathrm{~kb})$.

The CRLVaRNA is the second recognized luteovirus-associated RNA, supporting that the BWYV ST9aRNA is not an anomaly. The presence of the CRLVaRNA in the California CMD complex also demonstrates an even greater complexity than has been so far realized for the aphid-transmitted helper-dependent luteovirus complexes $(9,13,18)$.

\section{ACKNOWLEDGMENTS}

This research was funded by the California Fresh Carrot Advisory Board and the University of California. M. T. Watson and T. Tian contributed equally to this paper and should be considered as joint first authors. We thank M. Gibbs for the carrot mottle virus cDNA clone, and K. Suyenaga and H. Sliger for assistance with parts of this work. We also thank Z. Bao for dedicated and invaluable assistance. 


\section{LITERATURE CITED}

1. Altschul, S. F. 1991. Amino acid substitution matrices from an information theoretic perspective. J. Mol. Biol. 219:555-565.

2. Altschul, S. F., Gish, W., Miller, W., Myers, E. W., and Lipman, D. J. 1990. Basic local alignment search tool. J. Mol. Biol. 215:403-410.

3. Chin, L.-S., Foster, J., and Falk, B. W. 1993. The beet western yellows virus ST9-associated RNA shares structural and nucleotide sequence with the carmo-like viruses. Virology 192:473-482.

4. D'Arcy, C. J., Hewings, A. D., Burnett, P. A., and Jedlinski, H. 1983. Comparative purification of two luteoviruses. Phytopathology 73:755-759.

5. Dawson, W. O. 1983. Tobacco mosaic virus protein synthesis is correlated with double-stranded RNA synthesis and not single-stranded RNA synthesis. Virology 125:314-323.

6. Devereux, J., Haeberli, P., and Smithies, O. 1984. A comprehensive set of sequence analysis programs for the VAX. Nucleic Acids Res. 12:387-395.

7. Elnagar, S., and Murant, A. F. 1978. Relations of carrot red leaf and carrot mottle virus with their aphid vector, Cavariella aegopodii. Ann. Appl. Biol. 89:237-244.

8. Falk, B. W., Chin, L.-S., and Duffus, J. E. 1989. Complementary DNA cloning and hybridization analysis of beet western yellows luteovirus RNAs. J. Gen. Virol. 70:1301-1309.

9. Falk, B. W., and Duffus, J. E. 1981. Epidemiology of the helper-dependent aphid-transmitted virus complexes. Pages 162-179 in: Plant Diseases and Vectors: Ecology and Epidemiology. K. Maramorosch and K. F. Harris, eds. Academic Press, New York.

10. Falk, B. W., and Duffus, J. E. 1984. Identification of small single- and double-stranded RNAs associated with severe symptoms in beet western yellows virus-infected Capsella bursa-pastoris. Phytopathology 74: 1224-1229.

11. Gibbs, M. J., Cooper, J. I., and Waterhouse, P. M. 1996. The genome organization and affinities of an Australian isolate of carrot mottle umbravirus. Virology 224:310-313.

12. Huiet, L., Tsai, J. H., and Falk, B. W. 1992. Complete sequence of maize stripe virus RNA 4 and mapping of its subgenomic RNAs. J. Gen. Virol. 73:1603-1607.

13. Hull, R., and Adams, A. N. 1968. Groundnut rosette and its assistor virus. Ann. Appl. Biol. 62:139-146.

14. Koonin, E. V. 1991. The phylogeny of RNA-dependent RNA polymerases of positive-strand RNA viruses. J. Gen. Virol. 72:2197-2207.

15. Laemmli, U. K. 1970. Cleavage of structural proteins during the assembly of the head of bacteriophage T-4. Nature (Lond.) 227:680-685.

16. McMaster, G. K., and Carmichael, G. C. 1977. Analysis of single- and double-stranded nucleic acids on polyacrylamide and agarose gels using glyoxal and acridine orange. Proc. Natl. Acad. Sci. U.S.A. 74:4835-4837.

17. Murant, A. F. 1975. Occurrence of mottle and redleaf components of carrot motley dwarf disease in British Columbia. Can. Plant Dis. Surv. 55:103-105.
18. Murant, A. F. 1990. Dependence of groundnut rosette virus on its satellite RNA as well as on groundnut rosette assistor luteovirus for transmission by Aphis craccivora. J. Gen. Virol. 71:2163-2166.

19. Murant, A. F. Waterhouse, P. M., Raschke, J. H., and Robinson, D. J. 1985. Carrot red leaf and carrot mottle virus: Observations on the composition of the particles in single and mixed infections. J. Gen. Virol. 66: 1575-1579.

20. Passmore, B. K., Sanger, M., Chin, L.-S., Falk, B. W., and Bruening, G. 1993. A subviral, independently-replicating RNA stimulates the replication of beet western yellows luteovirus. Proc. Natl. Acad. Sci. U.S.A. 90: 10168-10172.

21. Rasochova, L., Passmore, B. K., Falk, B. W., and Miller, W. A. 1997. The satellite RNA of barley yellow dwarf virus-RPV is supported by beet western yellows in dicotyledonous protoplasts and plants. Virology 231:182-191.

22. Sanger, F., Nicklen, S., and Coulson, A. R. 1977. DNA sequencing with chain-terminating inhibitors. Proc. Natl. Acad. Sci. U.S.A. 74:5463-5467.

23. Sanger, M., Passmore, B., Falk, B. W., Bruening, G., Ding, B., and Lucas, W. J. 1994. Symptom severity of beet western yellows virus stain ST9 is conferred by the associated RNA and is not associated with virus release from the phloem. Virology 200:48-55.

24. Southern, E. M. 1975. Detection of specific sequences among DNA fragments separated by gel electrophoresis. J. Mol. Biol. 98:503-517.

25. Stubbs, L. L. 1948. A new virus of carrots: Its transmission, host range, and control. Aust. J. Sci. Res. B1:303-332.

26. Stubbs, L. L. 1952. Further host range and transmission studies with a virus disease of carrot endemic in Australia. Aust. J. Sci. Res. B5:399-408.

27. Stubbs, L. L. 1956. Motley dwarf disease of carrot in California. Plant Dis. Rep. 40:763-764.

28. Taliansky, M. E., Robinson, D. J., and Murant, A. F. 1996. Complete nucleotide sequence and organization of the RNA genome of groundnut rosette umbravirus. J. Gen. Virol. 77:2335-2345.

29. Valverde, R. A., Nameth, S. T., and Jordon, R. L. 1990. Analysis of double-stranded RNA for plant virus diagnosis. Plant Dis. 74:255-258.

30. Waterhouse, P. M., and Murant, A. F. 1981. Purification of carrot red leaf virus and evidence from four serological tests for its relationship to luteoviruses. J. Gen. Virol. 57:191-204.

31. Waterhouse, P. M., and Murant, A. F. 1983. Further evidence on the nature of the dependence of carrot mottle virus on carrot red leaf virus for transmission by aphids. Ann. Appl. Biol. 103:455-464.

32. Watson, M., Serjeant, E. P., and Lennon, E. A. 1964. Carrot motley dwarf and parsnip mottle viruses. Ann. Appl. Biol. 54:153-166.

33. Watson, M. T. 1994. California carrot motley dwarf: Identification and characterization of the viral agents associated with California carrot motley dwarf. Ph.D. dissertation. University of California, Davis.

34. Watson, M. T., and Falk, B. W. 1994. Ecological and epidemiological factors affecting carrot motley dwarf development in carrots grown in the Salinas Valley of California. Plant Dis. 78:477-481. 